\title{
One-Stage Direct-Vision Internal Urethrotomy and Penile Prosthesis Implantation for Severe Erectile Dysfunction with Urethral Stricture
}

\author{
Weidong Song, Yiguang Wu', Yiming Yuan, Jing Peng, Zhichao Zhang, Bing Gao, Xueyou He ${ }^{1}$ and Zhongcheng Xin* \\ Andrology Center, Peking University First Hospital, \\ ${ }^{1}$ Department of Urology, Chines PLA General Hospital, Beijing, China
}

\begin{abstract}
The safety and efficacy of one-stage direct-vision internal urethrotomy and penile prosthesis implantation (DVIU/PPI) in patients with severe erectile dysfunction (ED) combined with urethral stricture were investigated. Among the 108 cases of severe ED treated with PPI from June 2002 to May 2007, 5 patients with urethral stricture caused by a pelvic fracture or urethral injury underwent DVIU/PPI (AMS700CXM) upon the patient's request with informed consent. The patients were 20 35 years old and had been previously treated with a urethrourethral anastomosis. Erectile function and urinary function were evaluated by assessing the International Index of Erectile Function (IIEF5), the Quality of Life Index (QOL), the maximum urine flow rate (Qmax), and urethrography before and after the operation. The patients received follow-up examinations for 18 30 months. Two of the cases were confirmed as vasculogenic ED, and 3 were confirmed to be vasculogenic combined with neurogenic ED. The mean length of urethral stricture was $10.00 \pm 3.97 \mathrm{~mm}$. All 5 patients were successfully treated by one-stage DVIU/PPI under spinal anesthesia and were satisfied with both their sexual activity and their urinary function after surgery. The mean scores of the IIEF5, Qmax, QOL, and the diameter of the urethral stricture after surgery were $24.4 \pm 0.55,19.54 \pm 4.80 \mathrm{ml} / \mathrm{s}, 1.80 \pm 0.84$, and $7.16 \pm 0.43 \mathrm{~mm}$, respectively, which were significantly better than those before surgery $(p<0.05)$. No severe complications were noted in any of the 5 patients. In conclusion, one-stage DVIU/PPI might be an effective and safe procedure for treating patients suffering from severe ED combined with urethral stricture.
\end{abstract}

Key Words: Erectile dysfunction; Urethral stricture; Urethrotomy; Penile prosthesis

\section{Introduction}

Urethral injuries have been reported to occur in 3.5\% to $25 \%$ of all patients with pelvic fractures, with an overall mean of $14.5 \% .{ }^{1}$ Aşci et $\mathrm{al}^{2}$ reported that sexual and voiding dysfunction after pelvic fracture and posterior urethral injury seem to be the result of the

Accepted for Publication: March 25, 2009

*Corresponding author: Zhongcheng Xin, Andrology Center, Peking University First Hospital, Phone/FAX: +86-10-8322-2822, E-mail: xinzc@bjmu.edu.cn injury itself and not the result of any immediate treatment modalities.

The limited exposure in the open operation of urethrostenosis may cause further trauma and complications. For patients with a long urethral stricture or defect (> $2 \mathrm{~cm}$ ), multiple anastomosis failure, and complicated urethrostenosis, the endoscopic technique has become a more reliable and efficient treatment modality, ${ }^{3}$ with an overall success rate for direct-vision internal urethrotomy (DVIU) reaching $93 \%{ }^{4}$ 
On the other hand, erectile dysfunction (ED) is a common sequel of pelvic fractures, particularly those associated with posterior urethral injury as a result of damage to the cavernous nerves or branches of the pudendal arteries. The incidence rate of ED in patients with pelvic fracture combined with urethral injury has reached to $72 \% .^{5}$ Disruption of the cavernosal nerves lateral to the prostatomembranous urethra behind the symphysis pubis was the most likely cause of ED from this injury. ${ }^{6,7}$ The patterns of pelvic fracture might affect the incidence of ED, and a ruptured pubic symphysis appears to bear a risk of temporary ED. Posterior ring disruptions are possibly caused by nerve damage and seem to increase the risk of persistent, severe sexual dysfunction. ${ }^{8}$ When a pelvic fracture has taken place at the ischiadic ramus or as a butterfly fracture, it could damage the penile arteries or corpus cavernosus arteries, resulting in arterial ED. In passive perineal injuries of a pelvic fracture, the extruding convolution and shearing of the corpus cavernosum by the skeleton and muscle was the most important factor in incompetent closure of the cavernous veins, causing vasculogenic ED. ${ }^{5}$

Although oral medication of a phosphodiesterase-type 5 inhibitor (PDE5i) or intracavernosal injection (ICI) therapy is effective for patients with ED combined with urethral stricture, $60 \%$ of patients with neurogenic ED and $20 \%$ of those with arterial ED with pelvic fracture urethral disruption responded to sildenafil. ${ }^{9}$ Some severe ED patients with urethral stricture showed no response to PDE5i or ICI therapy. Penile prosthesis implantation (PPI) is commonly recommended after the management of urethral stricture for patients suffering from SED with urethral stricture; however, some patients strongly request one-stage surgery to cure their disease.

Accompanied by developments in surgical techniques, PPI has become the principal first-line treatment for severe ED. ${ }^{10-12}$ Rees et $\mathrm{al}^{13}$ reported their experiences in management of a low-flow priapism with the immediate insertion of a penile prosthesis. All 8 patients were satisfied with the end result, and 7 were having sexual intercourse. ${ }^{13}$ Zafirakis et $\mathrm{al}^{14}$ reported that the insertion of an artificial urinary sphincter (AUS) and PPI for the treatment of concurrent UI and ED was safe and effective. Both DVIU and PPI are established as ideal methods for treating urethral stricture and ED. However, one-stage DVIU and PPI has not been reported yet, possibly because of concern that DVIU might impose a risk factor for infection for PPI.

With recent technical improvements in DVIU and PPI, simultaneous PPI and DVIU became possible. Therefore, we investigated the safety and efficacy of one-stage DVIU/PPI for the treatment of severe ED patients with urethral stricture caused by pelvic fracture with urethral injury.

\section{Materials and Methods}

Among the 108 cases of severe ED treated with PPI from June 2002 to May 2007 in the Andrology Center of Peking University First Hospital, 5 patients with severe ED combined with urethral stricture caused by a pelvic fracture were treated with one-stage DVIU/PPI. All five patients, 20 35 years old, had been treated with urethrourethral anastomosis previously. Among them, 2 cases had partial urethral breakage and 3 had a complete urethral breakage. The mean time between hospitalization and injury was 4 years (range, 1 6 years).

The International Index of Erectile Function (IIEF5), sexual hormone analysis, NPT, CDDU, BCRLT, DNSEP test, and corpus cavernosus graph were used for the clinical evaluation of erectile dysfunction, and the therapeutic response to PDE5i was evaluated. The maximum urine flow rate (Qmax) and retrograde and anterograde urethrography cystoscopy were performed to evaluate the urethral stricture and urinary dysfunction. One-stage DVIU/PPI (AMS700CXM penile prosthesis) was performed at the patient's request under informed consent.

With the patient under spinal anesthesia, the DVIU was first performed according to current operating procedures. $^{15}$ Under the direct urethroscopic vision, a 
guidewire or a 5F ureteral catheter was passed through the scar fissure in order to define the direction. We prefer incisions in the 3 and 9 o'clock position and not in the 12 o'clock position to avoid damage to the corpus cavernosum. The incisions were made full-thickness through the depth of the scar and were not simple superficial lacerations. In short strictures, only one cut was enough, but longer strictures required multiple cuts. When the procedure was successfully completed, a twoway Foley's 20F size catheter was passed and left in place. Then, PPI (AMS700 CXM) was performed, without delay, following standardized operating procedures. ${ }^{10,14,16}$ The two-way Foley catheters were removed 2 weeks after the operation. The patients were instructed to attempt sexual intercourse 6 weeks after their surgery.

Postoperatively, the IIEF5, Quality of Life Index (QOL), Qmax, and urethrography were evaluated at 6 months after surgery.

Statistical analysis was performed by using SPSS (12.0, SPSS Inc., Chicago, IL, USA) with $\mathrm{p}$ values calculated by using Wilcoxon signed-rank test.

\section{Results}

All 5 patients were confirmed as having severe organic ED, and the mean score of the IIEF5 was $2.40 \pm 1.67$, including 2 cases of vasculogenic ED and 3 cases of combined vasculogenic and neurogenic ED. None of the patients responded to oral PDE5i. The urethral strictures were confirmed by Qmax, urethrography, and cystoscopy. The urethral injury locations were on the membranous urethra. The mean diameter of the point of the urethral stricture was $2.18 \pm 0.56 \mathrm{~mm}$, and the mean length of the stricture $10.00 \pm 3.97 \mathrm{~mm}$, which rendered catheter insertion difficult. The mean Qmax was $6.26 \pm 2.44 \mathrm{ml} / \mathrm{s}$ before surgery. The mean QOL scale of the patients measured $4.00 \pm 1.00$. All 5 patients were successfully implanted with a 3-piece AMS 700 CXM prosthesis after DVIU under spinal anesthesia without any complications. The mean surgery time was $34.00 \pm 8.22 \mathrm{~min}$ for DVIU and $78.00 \pm 8.37 \mathrm{~min}$ for PPI, making the total operation time $112.00 \pm 9.08 \mathrm{~min}$ (Table 1).

The incision healed well while the patients were given antibiotics for 14 days, and the Foley catheter was removed 2 weeks thereafter. All patients were given follow-up examinations in the outpatient clinic for $18 \sim$ 30 months. Patients were free from prosthesis infection, erosion, and mechanical complications. Three patients complained of local foreign body sensation and pain from pressurizing the pump in earlier postoperative periods, which were spontaneously relieved in 2 months. All patients and their partners were satisfied with their sexual life, with a mean IIEF5 score, QOL, Qmax, and diameter of the point of urethral stricture of $24.4 \pm 0.55$,

Table 1. Patient characteristics

\begin{tabular}{|c|c|c|c|c|c|}
\hline Patients & No. 1 & No. 2 & No. 3 & No. 4 & No. 5 \\
\hline Age & 30 & 32 & 33 & 35 & 20 \\
\hline Pelvic fracture style & Ischiadic ramus & Butterfly frcture & Ischiadic ramus & $\begin{array}{c}\text { Ruptured pubic } \\
\text { symphysis }\end{array}$ & Ischiadic ramus \\
\hline Duration of ED & 4 year & 2 year & 3.5 year & 6 year & 1 year \\
\hline Etiology of ED & Vasculogenic & $\begin{array}{l}\text { Vasculogenic } \\
\text { +neurogenic }\end{array}$ & Vasculogenic & $\begin{array}{l}\text { Vasculogenic } \\
\text { +neurogenic }\end{array}$ & $\begin{array}{l}\text { Vasculogenic } \\
\text { +neurogenic }\end{array}$ \\
\hline IIEF5 score, pre-OP & 1 & 1 & 3 & 5 & 2 \\
\hline Length of urethra stricture (mm) & 8.8 & 13.1 & 9.2 & 4.4 & 14.5 \\
\hline Maximum flow rate (Qmax), pre-OP (ml/s) & 3.6 & 5.2 & 4.8 & 8.8 & 8.9 \\
\hline $\mathrm{QOL}$ index, pre-OP & 5 & 5 & 4 & 3 & 3 \\
\hline Duration of $\mathrm{OP}$ (min) & 110 & 110 & 125 & 100 & 115 \\
\hline Follow-up (month) & 24 & 30 & 24 & 18 & 30 \\
\hline
\end{tabular}

$E D$, erectile dysfunction; OP, operation. 
Table 2. Clinical outcome of erectile function and urinary function after one stage direct vision internal urethrotomy and penile prosthesis implantation

\begin{tabular}{lrrr}
\hline \multicolumn{1}{c}{ Dimensions } & Pre-operation & Post-operation & $p$ value \\
\hline IIEF5 score & $2.40 \pm 1.67$ & $24.4 \pm 0.55$ & $<0.05$ \\
Maximum flow rate & $6.26 \pm 2.44$ & $19.54 \pm 4.80$ & $<0.05$ \\
(Qmax) (ml/s) & & & \\
Quality of life index (QOL) & $4.00 \pm 1.00$ & $1.80 \pm 0.84$ & $<0.05$ \\
Diameter of urethra & $2.18 \pm 0.56$ & $7.16 \pm 0.43$ & $<0.05$ \\
stricture (mm) & & & \\
\hline
\end{tabular}

Data presented as the mean \pm standard deviation from 5 patients

$1.80 \pm 0.84,19.54 \pm 4.80 \mathrm{ml} / \mathrm{s}$, and $7.16 \pm 0.43 \mathrm{~mm}$, respectively, all of which were significantly improved compared with the respective presurgical scores (Table 2, p $<0.05)$.

\section{Discussion}

Pelvic fracture is often combined with other organic damage, such as rectal injury, bladder injury, urethral injury, and erectile dysfunction. Voiding dysfunction and $\mathrm{ED}$ are the most common complications and might significantly influence quality of life for both male and female subjects. ${ }^{1,3,5}$

If medications such as oral PDE5i and intracavernous injection are ineffective, then patients often need PPI. Nowadays, the commonly used prostheses are the semi-rigid prosthesis and inflatable penile prosthesis. However, complications, such as uroschesis, pain in corpus cavernosum, or urethral perforation and erosion, often take place with a semi-rigid prosthesis, limiting the use of this procedure in the clinic. Also, it is not profitable to perform urethroscopy for those patients suffering from neurogenic bladder and ankylurethria or combined with prostatic hypertrophy. Therefore, the inflatable penile prosthesis seems to be more suitable for those patients.

Due to the complex structure and manipulation of the inflatable penile prosthesis, if there is no sufficient preoperational planning and well-versed manipulation, a long exposure time of the raw prosthesis surface could increase the incidence of complications, such as infection or mechanical failure. Wilson reported that the postoperative sepsis rate was $2.2 \%$ and the mechanical dysfunction rate $7.5 \%$ at the beginning of the operators' experience. ${ }^{11}$ Lane reported that more than $90 \%$ of 3-piece PPI were free of mechanical failure at year $5 .^{12}$ Dissatisfaction was mainly due to complications that resulted in the removal of the prosthesis. ${ }^{17}$

During the operation, we must insist on strict aseptic technique, on shortening the operation time as soon as possible, on proper irrigation of the corporum cavernosum with antibiotics repeatedly, and on persistent prevention of the penile urethra from being compressed by the rotation of the tubing and other procedures. ${ }^{18}$

Urethrotomy is a widely accepted procedure for the treatment of approximately $80 \%$ of patients with urethral strictures. ${ }^{15}$ The DVIU was an ideal surgery for urethral stricture that bears many advantages, such as safety, convenience, fewer complications, less aggravating degrees of difficulty from a second operation, and short length of stay after surgery. As for the urethral stricture with grave scar formation at the basement of the incision by cryoprobe, we could use electric or laser therapy to remove the scar thoroughly and dilate the urethra in time. However, internal urethrotomy is contraindicated when the length of stricture at the posterior urethra surpasses $2 \mathrm{~cm}$ or the stricture is combined with a stone, inflammatory polyps, urethral diverticulum, urethrorectal fistula, urethrocutaneous fistula, or spongiitis or with complications such as sphincter muscle of urethrasphincter dysfunction, false passage, severe pelvic deformity, pubic bone osteomyelitis, and severe vesical neck stricture. ${ }^{19,20}$ Due to improvements in techniques, the current success rate of DVIU is pretty high. Also, it did not increase the difficulty of a second DVIU or open surgery. Therefore, DVIU has become the first-line selection for urethrostenosis and urethratresia.

In our experience with DVIU and PPI for severe ED with urethral strictures, the key points for success include the following: 1) Indications for DVIU/PPI 
should be strictly limited to those patients with severe ED and urethral stricture without contraindication of PPI. The length of the stricture should be less than 2 $\mathrm{cm}$, and the procedures should be performed with the patient's request and informed consent. 2) Precise judgment on the urethratresia and urethrostenosis before surgery; correct identification of the normal urethral mucous membrane; and scars and the surrounding urethral tissue are free from damages of the genital duct and rectum. 3) Making incisions on the internal urethra at the 3 and 9 o'clock point, and not at the $12 \mathrm{o}^{\prime}$ clock point, to prevent exposure of the penile prostheses. 4) Keeping the Foley catheter for 2 weeks in order to raise the healing rate, postoperative rehabilitation, and attendance. 5) Shorten the operation time of PPI, prevent tissue damage for as long as possible, and repeatedly irrigate the corporum cavernosum with antibiotics. 6) Prevent penile urethral compression.

With the development of DVIU and PPI, synchronous PPI and DVIU has become possible. The advantages of this approach are a single anesthesia, shorter hospital stay, and cost savings.

In conclusion, the present results indicate that one-stage DVIU/PPI might be an effective and safe clinical procedure for treating patients with severe ED combined with urethral stricture. Further studies are needed to prove the safety of this procedure.

\section{References}

1. Webster GD, Mathes GL, Selli C. Prostatomembranous urethral injuries: a review of the literature and a rational approach to their management. J Urol 1983;130:898-902.

2. Aşci R, Sarikaya S, Büyükalpelli R, Saylik A, Yilmaz AF, Yildiz S, et al. Voiding and sexual dysfunctions after pelvic fracture urethral injuries treated with either initial cystostomy and delayed urethroplasty or immediate primary urethral realignment. Scand J Urol Nephrol 1999;33:228-33.

3. Moudouni SM, Patard JJ, Manunta A, Guiraud P, Lobel B, Guillé F, et al. Early endoscopic realignment of post-traumatic posterior urethral disruption. Urology 2001;57:628-32.

4. Cooperberg MR, McAninch JW, Alsikafi NF, Elliott SP. Urethral reconstruction for traumatic posterior urethral disruption: outcomes of a 25-year experience. J Urol 2007;178:2006-10.

5. Shenfeld OZ, Kiseigorf D, Gofrit ON, Verstandig AG, Landau EH, Pode D, et al. The incidence and causes of erectile dysfunction after pelvic fractures associated with posterior urethral disruption. $J$ Urol 2003;169:2173-6.

6. Mark SD, Keane TE, Vandemark RM, Webster GD. Impotence following pelvic fracture urethral injury: incidence, aetiology and management. Br J Urol 1995;75:62-4.

7. Metze M, Tiemann AH, Josten C. Male sexual dysfunction after pelvic fracture. J Trauma 2007;63:394-401.

8. Malavaud B, Mouzin M, Tricoire JL, Gamé X, Rischmann P, Sarramon JP, et al. Evaluation of male sexual function after pelvic trauma by the International Index of Erectile Function. Urology 2000 ;55:842-6.

9. Shenfeld OZ, Gofrit ON, Gdor Y, Landau I, Katz R, Pode D, et al. The role of sildenafil in the treatment of erectile dysfunction in patients with pelvic fracture urethral disruption. J Urol 2004;172: 2350-2.

10. Montague DK. Prosthetic surgery for erectile dysfunction, in Wein AJ, Kavoussi LR, Novick AC, et al(Eds):Campbell-Walsh Urology, 9th ed, Philadelphia, WB Saunders, 2007;788-801.

11. Wilson SK, Delk JR, Salem EA, Cleves MA. Long-term survival of inflatable penile prostheses: single surgical group experience with 2,384 first-time implants spanning two decades. J Sex Med 2007;4: $1074-9$.

12. Lane BR, Abouassaly R, Angermeier KW, Montague DK. Three-piece inflatable penile prostheses can be safely implanted after radical prostatectomy through a transverse scrotal incision. Urology 2007;70: $539-42$.

13. Rees RW, Kalsi J, Minhas S, Peters J, Kell P, Ralph DJ, et al. The management of low-flow priapism with the immediate insertion of a penile prosthesis. BJU International 2002;90:893-7.

14. Zafirakis H, Wang R, Westney OL. Combination therapy for male erectile dysfunction and urinary incontinence. Asian J Androl 2008;10: $149-54$.

15. Matouschek E. Internal urethrotom of urethral stricture under-vision-a five-year report. Urol Res 1978;6:147-50.

16. XIN Zhongcheng, GUO Yinglu, Choi HK. A retrospective study of 548 cases of erectile dysfunction treated by penile prosthesis implantation. Chin J Urol 2000;21:755-7.

17. Minervini A, Ralph DJ, Pryor JP. Outcome of penile prosthesis implantation for treating erectile dysfunction: experience with 504 procedures. BJU Int 2006;97:129-33.

18. Lee SW, Park BH, Lim JH, Cui WS, Kim MK, Park JK, et al. Prevention of urethral stricture in insertion of an inflatable penile prosthesis. Int $J$ Urol 2008;15:162-5.

19. Hafez AT, El-Assmy A, Dawaba MS, Sarhan O, Bazeed M. Long-term outcome of visual internal urethrotomy for the management of pediatric urethral strictures. J Urol 2005;173:595-7.

20. Altinova S, Turkan S. Optical urethrotomy using topical anesthesia. Int Urol Nephrol 2007;39:511-2. 